Edith Cowan University

Research Online

Research outputs 2014 to 2021

$12-1-2019$

\title{
General practitioners' perceptions of their communication with Australian Aboriginal patients with acquired neurogenic communication disorders
}

\author{
Deborah Hersh \\ Edith Cowan University \\ Elizabeth Armstrong \\ Edith Cowan University \\ Meaghan McAllister \\ Edith Cowan University \\ Natalie Ciccone \\ Edith Cowan University \\ Judith Katzenellenbogen
}

See next page for additional authors

Follow this and additional works at: https://ro.ecu.edu.au/ecuworkspost2013

Part of the Medicine and Health Sciences Commons

10.1016/j.pec.2019.07.029

This is an Author's Accepted Manuscript of: Hersh, D., Armstrong, E., McAllister, M., Ciccone, N., Katzenellenbogen, J., Coffin, J., ... Woods, D. (2019). General practitioners' perceptions of their communication with Australian Aboriginal patients with acquired neurogenic communication disorders. Patient Education and Counseling, 102(12), 2310-2317. Available here

(C) 2019. This manuscript version is made Available under the CC-BY-NC-ND 4.0 license

http://creativecommons.org/licenses/by-nc-nd/4.0/

This Journal Article is posted at Research Online.

https://ro.ecu.edu.au/ecuworkspost2013/7196 


\section{Authors}

Deborah Hersh, Elizabeth Armstrong, Meaghan McAllister, Natalie Ciccone, Judith Katzenellenbogen, Juli Coffin, Sandra Thompson, Colleen Hayward, Leon Flicker, and Deborah Woods 
(C) 2019. This manuscript version is made available under the CC-BY-NC-ND 4.0 license http://creativecommons.org/licenses/by-nc-nd/4.0/

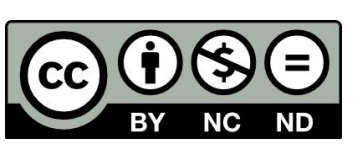




\section{Accepted Manuscript}

Title: General practitioners' perceptions of their communication with Australian Aboriginal patients with acquired neurogenic communication disorders

Authors: Deborah Hersh (Conceptualization) (Data curation)

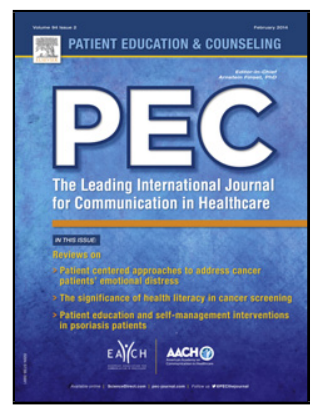
(Formal analysis) (Writing - original draft), Elizabeth Armstrong (Conceptualization) (Funding acquisition) (Project administration) (Data curation) (Formal analysis) (Writing original draft), Meaghan McAllister (Conceptualization) (Project administration) (Data curation) (Formal analysis), Natalie Ciccone (Conceptualization) (Data curation) (Formal analysis), Judith Katzenellenbogen (Conceptualization) (Writing - review and editing), Juli Coffin (Validation) (Conceptualization) (Writing - review and editing), Sandra Thompson (Conceptualization) (Writing - review and editing), Colleen Hayward (Writing - review and editing), Leon Flicker (Conceptualization) (Writing - review and editing), Deborah Woods (Writing - review and editing)

PII: S0738-3991(19)30314-3

DOI: https://doi.org/10.1016/j.pec.2019.07.029

Reference: PEC 6345

To appear in: $\quad$ Patient Education and Counseling

Received date: $\quad 24$ February 2019

Revised date: $\quad 12$ July 2019

Accepted date: $\quad 23$ July 2019

Please cite this article as: Hersh D, Armstrong E, McAllister M, Ciccone N, Katzenellenbogen J, Coffin J, Thompson S, Hayward C, Flicker L, Woods D, General practitioners' perceptions of their communication with Australian Aboriginal patients with acquired neurogenic communication disorders, Patient Education and Counseling (2019), https://doi.org/10.1016/j.pec.2019.07.029

This is a PDF file of an unedited manuscript that has been accepted for publication. As a service to our customers we are providing this early version of the manuscript. The manuscript will undergo copyediting, typesetting, and review of the resulting proof before it is published in its final form. Please note that during the production process errors may be discovered which could affect the content, and all legal disclaimers that apply to the journal pertain. 
General practitioners' perceptions of their communication with Australian Aboriginal patients with acquired neurogenic communication disorders

Deborah Hersh a, Elizabeth Armstrong a, Meaghan McAllister ${ }^{\text {a }}$, Natalie Ciccone ${ }^{\text {a }}$, Judith Katzenellenbogen ${ }^{b, c}$, Juli Coffin ${ }^{b}$, Sandra Thompson ${ }^{c}$, Colleen Hayward ${ }^{\text {a }}$, Leon Flicker ${ }^{c, d}$, Deborah Woods ${ }^{\mathrm{e}}$.

a Speech Pathology, Edith Cowan University, Perth, Australia

${ }^{\mathrm{b}}$ Telethon Kids Institute, Broome and Perth, Australia

${ }^{c}$ WA Centre for Rural Health, University of Western Australia, Perth, Australia

${ }^{d}$ Royal Perth Hospital \& University of Western Australia, Perth, Australia

e Geraldton Regional Aboriginal Medical Service, Geraldton, Australia

Corresponding author at:

Associate Professor Deborah Hersh, School of Medical and Health Sciences, Edith Cowan University, 270 Joondalup Drive, Joondalup, WA, 6027.

Telephone: +61-8- 63042563

d.hersh@ecu.edu.au 
- Acquired communication disorders (ACD) in Aboriginal patients challenge GPs

- GPs rely on families and Aboriginal Health Workers as interpreters

- GPs rarely refer Aboriginal adults to speech pathology for communication

- GPs would benefit from more cultural safety and communication training for ACD

\begin{abstract}
Objective

Aboriginal people have high rates of stroke and traumatic brain injury (TBI), often with residual, chronic communication deficits and multiple co-morbidities. This study examined general practitioners' (GPs') perceptions of their communication with Aboriginal patients with acquired communication disorders (ACD) after brain injury. Effective communication underpins good care but no previous research has explored this specific context.
\end{abstract}

\title{
Methods
}

A qualitative descriptive approach was employed using interviews and focus groups with 23 GPs from metropolitan Perth and five regional sites in Western Australia. Data were analysed thematically.

\section{Results}

GPs reported low visibility of Aboriginal patients with ACD in their practices, minimal training on neurogenic $A C D$, and difficulty distinguishing $A C D$ from cultural-linguistic factors. They had few communication resources, and depended on families and Aboriginal 
Health Workers to assist in interactions. They rarely used formal interpreting services or referred to speech pathology. They reported communication (dis)ability having low priority in consultations.

\section{Conclusion}

GPs report difficulty recognising $A C D$ and their lack of prioritising assessment and treatment of communication ability after brain injury potentially compounds the disadvantage and disempowerment experienced by many Aboriginal people.

\section{Practice Implications}

GPs require further communication and cultural training. Improved access to speech pathology and formal interpreting services would be beneficial. 


\section{General practitioners' perceptions of their communication with Australian Aboriginal patients with acquired neurogenic communication disorders}

\section{Introduction}

Australia's First Peoples - Aboriginal and Torres Strait Islander populations (hereafter referred to as Aboriginal Australians), are estimated to be $3.3 \%$ of the total Australian population. Western Australia (WA), an area of over 2.5 million $\mathrm{km}^{2}$, has its population of approximately 2.7 million people mainly centred around the capital, Perth, and the south west region of the state. WA is home to approximately 100,000 Aboriginal people (about $15 \%$ of Aboriginal Australians nationally) who live across urban, regional and remote WA.

For Aboriginal Australians, stroke, a debilitating condition, occurs up to three times more frequently, and at younger ages, compared to non-Aboriginal Australians [1]. Traumatic brain injury (TBI) is also found at much higher rates, particularly in association with assault [2,3]. Approximately a third of people following stroke and TBI have some level of persisting acquired communication disorder (ACD) [4,5]: aphasia (a disorder of language understanding and/or expression); dysarthria (speech disorder, often causing slowness and slurring); dyspraxia (problems with motor planning for speech); and cognitive communication disorder (difficulties with aspects of social communication, discourse and pragmatic skills, attention, memory, and executive functioning). In the clinical setting, an ACD can make it difficult for patients to contribute to decisions and can leave them in a disempowered position in health care encounters [6-8]. ACD adds to the already challenging issue of practitioner/client communication which has been repeatedly highlighted as being problematic for both primary healthcare providers and Aboriginal clients [9-15]. The general 
literature on doctor-patient interactions highlights potential asymmetries in both withincultural [16-18] and cross-cultural interactions $[19,20]$, and notes the challenges facing health practitioners particularly in terms of the latter. Therefore, it is not surprising that interactions between healthcare practitioners and Aboriginal clients are often reported to involve miscommunication and breakdown of communication. In the Australian context, common difficulties include a lack of understanding of Aboriginal English as opposed to Standard Australian English [21], and difficulties interpreting the fundamentally different modes of discourse used by non-Aboriginal health practitioners and many Aboriginal patients [11]. For example, the question/answer style that constitutes the typical healthcare 'interview' genre does not necessarily align with expectations of directness of many Australian Aboriginal discourses. Other examples include cultural differences in the construction of a "story", the use of silence as a strategy to get more comfortable with a particular situation $[22,23]$ and the rules surrounding what kinds of information can be given to whom $[22,24]$. Health practitioners also express reservations in asking about personal and lifestyle issues as part of health checks, which they often feel are "difficult, sensitive or invasive" [25,p.153]. Additionally, Aboriginal communities represent diversity of language and culture with over 120 Aboriginal language groups existing, and few formal interpreting or cultural brokering services available.

The layering of challenges in communication due to neurological damage, cultural and language differences, suggests that the delivery of primary health care by general practitioners (GPs) to Aboriginal people with brain injury requires investigation. GPs are key gatekeepers to services and often the first community-level point of contact into the health system. The context is further complicated because the sequelae of brain injury often require long term, multidisciplinary physical and cognitive rehabilitation which the GP may 
be expected to coordinate. Additionally, survivors with ACD may be particularly dependent on family and carers for everyday activities, and often lose the ability to advocate for themselves or influence decisions about important life issues. There are often multiple issues related to management of particular health conditions, (for example, the monitoring of blood sugar levels in diabetes, or the taking of medications), alongside concerns about psychosocial status, ability to undertake activities of daily living, long term recovery goals and quality of life [26-29]. In addition, histories of multiple strokes or head injuries, as well as complex pre-existing co-morbidities, are common [2]. For all these reasons, it is important to understand how GPs view their communication with Aboriginal patients with $\underline{A C D}$, their ability to judge what these patients want, and to support their patients' involvement in health care decision-making. This has not previously been addressed in any studies in Australia, or in other First Nations contexts, such as in New Zealand or Canada, where large health disparities exist. A clearer understanding of GPs' perceptions may inform what further training or supports they need to best work with their Aboriginal patients in $\underline{\text { such a complex context. }}$

The current study explores GPs' perceptions of their communication with Aboriginal people with $A C D$, and their views of communication-related issues. The data reported here are part of the larger Missing Voices research project [30] funded through the Australian National Health and Medical Research Council. This work complements the perspectives of Aboriginal people with ACD and their families, Aboriginal Health Workers (AHWs) and Speech Pathologists, also collected in the Missing Voices project (forthcoming).

\section{Materials and methods}

This research used a qualitative descriptive, inductive methodology [31] and sought access to GPs who had some level of experience working with Aboriginal patients. Three 
non-Aboriginal interviewers, who were all experienced speech pathologists and qualitative researchers, collected data using audio-recorded, semi-structured interviews and focus groups [32]. Over a two-year period, alongside other data collection for other aspects of Missing Voices [30], 23 GPs (11 male; 12 female) were interviewed (18 face to face and five via teleconference due to the logistics of time and travel across large distances). accessed through contacting GP practices and Aboriginal Community Controlled Health Organisations (ACCHOs, also referred to by the participants as Aboriginal Medical Services or AMS which employ GPs), from Perth and the five regional sites in WA participating in Missing Voices. In line with maximal variation sampling [33] we were interested in talking to male and female GPs, with different levels of experience, working across the different sites. Of the GP practices contacted in each site, all were happy to include at least one GP to be interviewed but individuals' schedules, timing and availability (not always when a researcher was visiting the site) meant that some had to be interviewed by teleconference. For two regional and one Perth site, a focus group format allowed access to the views of several staff in one session. None of the GPs were Aboriginal or spoke an Aboriginal language. Nine of the 23 GPs were speakers of English as an additional language, and they represented a variety of ethnic and linguistic backgrounds. The characteristics of participants are shown in Table 1. Interviews lasted about an hour. The topic guide included broad open questions with opportunities for prompting and funnelling questions, and asked participants to talk about their perceptions of the following: experiences to date with Aboriginal patients with $\underline{A C D}$ after stroke or brain injury; strategies used to ensure a satisfying consultation with patients; services provided; any training received to assist with interaction with patients with ACD; knowledge of community-based services (including speech pathology) and 
referral practices; comments or suggestions on models of service delivery that might assist access to services in the context of communication disorder; any other comments.

This paper reports specifically on interview data about GPs' perceptions of their communication with Aboriginal patients with $A C D$ and issues related to communication. $\underline{A}$ second paper (forthcoming) focuses more broadly on their working contexts, their decisionmaking, and the issues they view as important or challenging in the care of their Aboriginal patients with $A C D$.

Table 1: Participant characteristics (nk = not known; EAL = English as an additional language)

\begin{tabular}{|c|c|c|c|c|c|c|c|}
\hline GP & Gender & $\begin{array}{l}\text { Years } \\
\text { since } \\
\text { qualifying }\end{array}$ & Location & $\begin{array}{l}\text { Years of } \\
\text { experience with } \\
\text { Aboriginal } \\
\text { clients }\end{array}$ & EAL & $\begin{array}{l}\% \\
\text { Aboriginal } \\
\text { caseload }\end{array}$ & $\begin{array}{l}\text { Individual } \\
\text { (I) or focus } \\
\text { group (FG) }\end{array}$ \\
\hline 1 & $M$ & 23 & $\begin{array}{l}\text { Regional/rural (GP } \\
\text { practice) }\end{array}$ & 15 & $\mathrm{~N}$ & $30 \%$ & 1 \\
\hline 2 & $\mathrm{~F}$ & nk & Regional/rural (ACCHO) & 18 & $Y$ & $85 \%$ & 1 \\
\hline 3 & $\mathrm{~F}$ & 25 & $\begin{array}{l}\text { Regional/rural (GP } \\
\text { practice) }\end{array}$ & 15 & $\mathrm{~N}$ & $90 \%$ & 1 \\
\hline 4 & $M$ & 29 & $\begin{array}{l}\text { Regional/rural (GP } \\
\text { practice) }\end{array}$ & 6 & $Y$ & $90 \%$ & I \\
\hline 5 & M & $\mathrm{nk}$ & Regional/rural (ACCHO) & 15 months & $Y$ & $100 \%$ & FG \\
\hline 6 & $\mathrm{~F}$ & nk & Regional/rural (ACCHO) & "many years" & $\mathrm{N}$ & $100 \%$ & FG \\
\hline 7 & $M$ & 23 & Perth metro (ACCHO) & 8 & Y & $25 \%$ & FG \\
\hline 8 & M & 11 & Perth metro (ACCHO) & 5 & $Y$ & & FG \\
\hline 9 & M & 19 & Perth metro (ACCHO) & 3 & $Y$ & $100 \%$ & $\mathrm{FG}$ \\
\hline 10 & M & $\mathrm{nk}$ & $\begin{array}{l}\text { Perth metro (GP } \\
\text { practice) }\end{array}$ & 11 & $Y$ & $100 \%$ & I \\
\hline 11 & $\mathrm{~F}$ & 24 & $\begin{array}{l}\text { Perth metro (GP } \\
\text { practice) }\end{array}$ & 24 & $\mathrm{~N}$ & $15 \%$ & I \\
\hline 12 & $M$ & nk & Regional/rural (ACCHO) & nk & $\mathrm{N}$ & $100 \%$ & I \\
\hline
\end{tabular}




\begin{tabular}{|c|c|c|c|c|c|c|c|}
\hline 13 & $\mathrm{~F}$ & $\mathrm{nk}$ & $\begin{array}{l}\text { Regional/rural (GP } \\
\text { practice) }\end{array}$ & 3 & $\mathrm{~N}$ & $50 \%$ & 1 \\
\hline 14 & $M$ & $\mathrm{nk}$ & $\begin{array}{l}\text { Regional/rural (GP } \\
\text { practice) }\end{array}$ & 6 & $\mathrm{~N}$ & $80 \%$ & 1 \\
\hline 15 & $\mathrm{~F}$ & 30 & $\begin{array}{l}\text { Perth metro (GP } \\
\text { practice) }\end{array}$ & 15 & $\mathrm{~N}$ & $100 \%$ & 1 \\
\hline 16 & M & 3 & $\begin{array}{l}\text { Regional/rural (GP } \\
\text { practice) }\end{array}$ & 3 & $\mathrm{~N}$ & $90 \%$ & FG \\
\hline 17 & $\mathrm{~F}$ & 10 & $\begin{array}{l}\text { Regional/rural (GP } \\
\text { practice) }\end{array}$ & 5 & $\mathrm{~N}$ & $90 \%$ & FG \\
\hline 18 & $\mathrm{~F}$ & 17 & $\begin{array}{l}\text { Regional/rural (GP } \\
\text { practice) }\end{array}$ & 5 & $\mathrm{~N}$ & $90 \%$ & FG \\
\hline 19 & $\mathrm{~F}$ & 6 & Regional/rural (ACCHO) & 6 & $\mathrm{~N}$ & $90 \%$ & FG \\
\hline 20 & $M$ & 19 & Regional/rural (ACCHO) & 7 & $\mathrm{~N}$ & $100 \%$ & 1 \\
\hline 21 & $\mathrm{~F}$ & $\mathrm{nk}$ & Regional/rural (ACCHO) & 4 & $\mathrm{~N}$ & $90 \%$ & 1 \\
\hline 22 & $\mathrm{~F}$ & 14 & Regional/rural (ACCHO) & 3 & $Y$ & $95 \%$ & I \\
\hline 23 & $\mathrm{~F}$ & 20 & Regional/rural (ACCHO) & 8 & $Y$ & $90 \%$ & I \\
\hline
\end{tabular}

All interview/focus group transcripts were transcribed verbatim. Transcripts were uploaded to NVivo 10 [34] to manage the data and facilitate thematic analysis [35]. The first two authors analysed the full data set and four team members also read through $30 \%$ of the texts (6 participant texts each) to check the coding and reach consensus regarding the coding and themes/subthemes generated through the process.

Ethical approval for the overall project was obtained through two University Human Research Ethics Committees, the Western Australian Aboriginal Health Ethics Committee, the Southern Metropolitan Health Service, and the Western Australian Country Health Service Research Ethics Committee. Approval was also obtained from four ACCHO Boards.

\section{Results}


Six key interrelated themes about GP perceptions of communication with their Aboriginal patients with ACD were developed inductively from the analysed data and are summarised in Figure 1.

Figure 1: Six themes related to GPs' perceptions of communication with Aboriginal patients with ACD

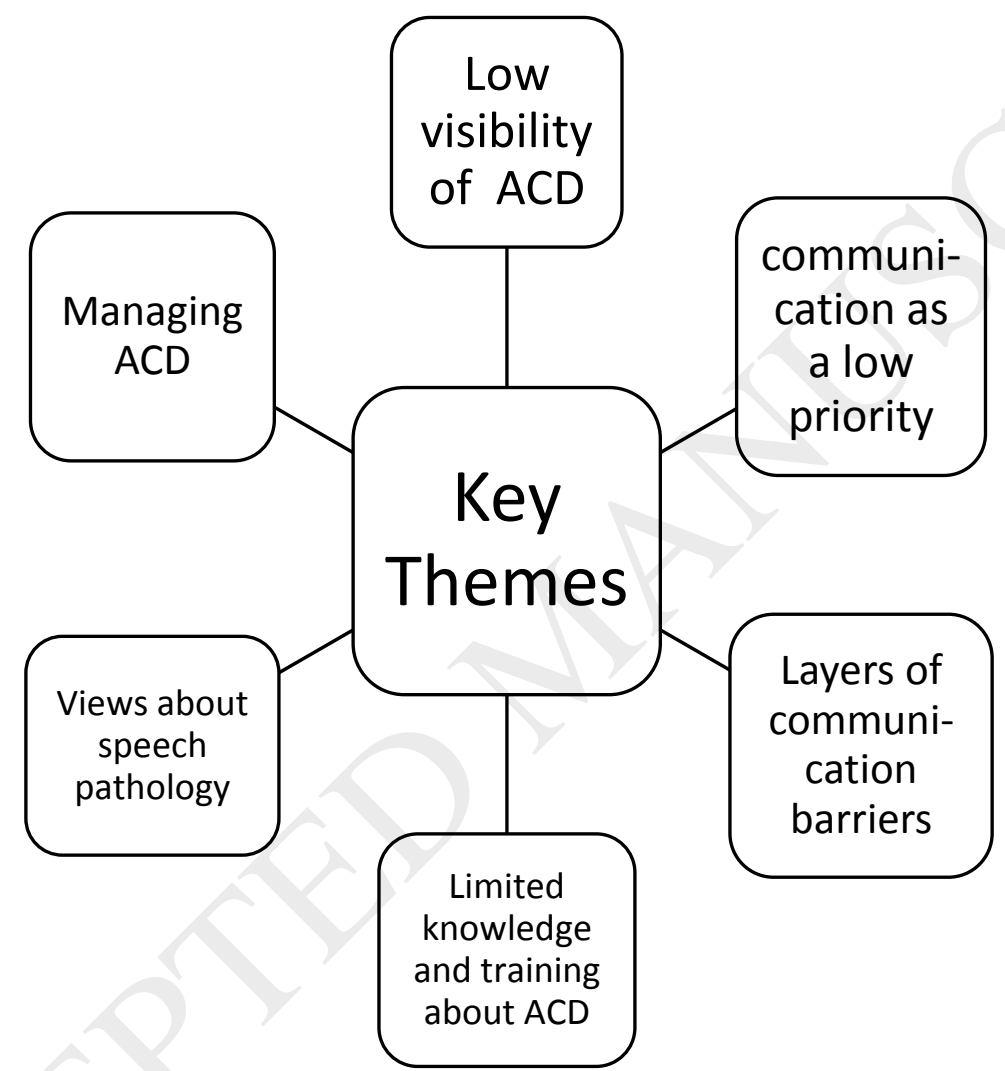

\section{Theme 1. Low visibility of ACD in caseloads}

Overall, GPs reported that they rarely had patients on their caseloads where ACD was a prominent issue: "I can't think of any where they've turned up with a speech problem as their presenting problem" (GP 6). Sometimes their comments reflected an acknowledgement that this was a curious situation considering the high rates of stroke and TBI and likelihood of chronic communication disabilities in Aboriginal populations. Mainly, 
they focused on the high levels of complex medical and social issues for their Aboriginal patients which required considerable time and coordination of care:

But they will have co-morbidities. And they have mostly got something, everything else wrong as well. Mostly have diabetes and heart problems and renal problems as well. (GP 15)

I can't think of that [a communication disorder] ever being the main presenting complaint... I think it kind of becomes one of many things that's going on with that person, doesn't it? ... In the setting that I work in, the family support is often very good so maybe I notice it less than I have in other settings that I've worked in. (GP 21)

This situation, along with their generalist focus, and need to address urgent medical concerns, meant that any co-existing ACD did not necessarily feature prominently during consultations:

Mostly as a GP, you're faced with a presenting complaint and the aphasia or dysphasia is actually a secondary thing. (GP 11)

You just treat the problem they've come with unless they bring it up as problem so... I guess there's probably missed opportunities. (GP 6)

An example of this was when GP 2 recounted her management of a patient who had speech and hearing difficulties post-stroke in addition to diabetes and multiple other conditions: "...so we honestly could not concentrate much on her speech... so speech got shoved" (GP 2). While a number of participants did report experiences managing patients with a range of ACDs, there were suggestions that identification of such disorders might be low or that only very severely impaired people would be picked up in general practice:

So I actually think one of the issues is in identifying these patients and having staff that have an awareness of the fact that they may have a communication difficulty. We pick it up when there's an obvious issue. (GP 17) 
...like if it is quite significant then we come to know but if it is borderline maybe we are missing them. So I will say, it will be good if we have some proper guidelines... at least some protocol... (GP23)

\section{Theme 2: Assumptions of low health literacy and low patient prioritisation of communication support}

Several GPs highlighted that Aboriginal patients often had low literacy, needed extra supports with written information, regardless of ACDs, and were usually not well informed about their health issues.

So the mob up here is not widely read unless you've got a computer, and you've got to have access too for a computer, and that urgency to go on a computer to read and get up-to-date information. (GP 20)

I think the concept of literacy level needs to be taken on board by clerical staff in hospitals and they need to realise that all correspondence by hospitals needs to be written as though people's literacy levels are very low. (GP 11)

GPs reported that their patients did not ask for help with their ACDs, were not aware of speech pathology services, and said that the needs of their family, community and culture came before their own health needs:

Hardly ever [requesting help] in relation to their speech. It's much more about their mobility... (GP 15)

So for the rehab, I would say, 20\% of Aboriginal patients are really good, they want to do everything, like health is priority... But for $80 \%$ of patients, health is not a priority... And there is like a lot of socioeconomic issues... family issues so... they don't want to give much attention to these things... Like elderly patients, lot of them will be coming with the grandkids and they will say, I don't have time to worry about myself. (GP 23)

One GP felt that patients might feel shame [36] about a communication problem and a reluctance to raise the issue: 
I think there's shame probably about it all. I mean I think they feel very embarrassed. I mean that they're... though I think that's probably for everybody, but it might be, probably more for Aboriginal people. (GP 15)

Finally, there was a suggestion from one GP that Aboriginal patients just wanted "basic communication". The quote below contains a range of assumptions and generalisations which are concerning:

I think also often it's people's aspirations aren't very high and as long as they can get the activities of daily living sorted out, the rest of it, you know, it's like 'I don't really have time'... Also I think this concept of being highly coherent is an aspiration of the well-educated and it is not an aspiration of people who aren't well educated and don't have high aspirations for their lives and so, being highly articulate I guess is what I mean, like they don't even aspire to that. They just aspire to be able to get what they're saying, just basic communication. And so I'm not really sure if a lot of them even see it as a problem... And also you've got to realise that there's all that non-verbal communication that people do, that maybe they are managing through some of that. And maybe they haven't lost that. So I think, I don't get people saying 'I really need some help with my speech'. (GP 3)

Theme 3: Layers of communication: neurological, cultural, and language differences

GPs found it hard to tease apart the possible factors contributing to communication difficulties with their Aboriginal patients. They struggled to see the acquired neurological symptoms of aphasia, dyspraxia and dysarthria in the context of other aspects of their patients' communication:

I saw a patient once, he was in town from a remote area... but I couldn't communicate properly with him... Like there was me thinking he had a dysphasia but actually it was just that English was probably his fourth language. (GP 11)

So sometimes we'll get patients that don't really talk to us at all at the best of times so differentiating that between... a receptive dysphasia or something like that, it makes it a little bit tricky. Or a global dysphasia. (GP 14) 
The situation was felt to be exacerbated by complex histories with multiple comorbidities

potentially contributing to the communication:

You'd be struggling to communicate with them and you knew they'd had head injuries in the past and you just didn't quite know what that was about and is it because they actually don't speak much English or is it actually because they are dysarthric? ...And there are so many health and social issues with those people, you know, that's just one of a dozen things that you could be addressing in that consult while you're trying to fix their broken arm so you don't always go there. (GP 11)

Some GPs mentioned patients' difficulties due to language and cultural difference, or a reticence to communicate related to a history of colonisation, racism and disadvantage. GPs noted that English might be a second, third or fourth language, that patients might use "locally relevant" (GP 1) dialects, or be reluctant to engage in conversation unless there was an existing, trusting relationship. GP 1 mentioned that the situation might be more difficult for doctors, who themselves, had English as an additional language:

But what I've noticed is they also seem to struggle with English, struggle with communicating... they certainly don't communicate like we do in English and I've noticed that our GP registrars, particularly if they've come from another culture, have trouble understanding our Aboriginal patients... Typically, Aboriginal people have often just mixed and communicated and talked among themselves, so they don't communicate in a really defined creole type of way but it is idiosyncratic, well not idiosyncratic. It's a type of communication that is very local, locally relevant to them. (GP 1)

I would actually argue that most of the Aboriginal patients probably find it hard to advocate for themselves when they're particularly from a far-away place... They're down in big centres in Perth, I think they find it very difficult to communicate anyway, so maybe the stroke or the acquired injury makes it obvious that they're not able to communicate but actually I would say that that difficulty might be there anyway. (GP 17)

Assessment is difficult especially if I don't know them to start with... they are often reluctant to communicate with a new white person especially anyway... It's like: are they just not talking to me because they don't want to? Or are they actually finding it hard to find the word or cannot find the word? So it is tricky. For young people it would be a lot more obvious I think but if a person came through the door and just was silent it would be often they are terrified which is understandable so it would be difficult to ascertain the extent of their speech impairment. (GP 13) 
Theme 4: Limited knowledge and training about ACD

Many participants reported very little specific training about ACDs in medical school, although some felt they knew "the basics" (GP 14).

I mean I don't ever remember ever receiving a lecture or anything from a speech therapist anytime in my medical school training. Ever. (GP 3)

So I know the basics, I guess. Differences between dysphasia and dysphagia and dysarthria and all of those things. (GP 14)

I think that's been quite limited. That training, yes. And, you know, it's an interesting thing to reflect on... if your training's been limited then you won't recognise it as a health problem. (GP 1)

However, considering the difficulties they had distinguishing ACDs from cultural and linguistic differences, the level of training they reported appeared insufficient for them to be confident with recognition of ACD within their often complex caseloads. GP 17 noted that it was not a prominent issue: "while we learn it during medical school... it's tossed in amongst all the other training of things that you learn..." While GPs often noted cognitive damage in their patients, they did not mention cognitive-communication disorders at all, and most were aware that milder presentations of communication disorders were likely to be missed. GP 12 saw a paradox that the training was inadequate considering: "the basics of general practice, and being country doctors, good communication...that's the basis. Any amount of more training would be great..."

Theme 5: Few referrals to SP; low knowledge about SP; viewed as inaccessible and limited 
In the light of the findings in Theme 4, it was unsurprising that GPs reported a low level of knowledge about speech pathology for $A C D$, and what might be offered: "What actually can you do to improve this person's speech? I suppose we're just ignorant" (GP 15).

GPs were more aware of speech pathology services for children:

The other thing about speech therapy is of course it is quite a big thing on people's radar with the children you know, because the speech delay is huge. (GP 15)

Many reported regularly making referrals for children but never for adults for communication. For example, GP 22 who had worked for three years in an ACCHO, had never referred an adult for speech pathology: “Oh no. Ah. No, not actually an adult, but a lot of kids... Yeah, a lot of kids" (GP 22). GP 11 had worked for 24 years and never referred an adult to speech pathology, whether Aboriginal or not: "For kids, obviously, but for adults... No, I don't think I have for adults ever" (GP11). In contrast to being able to "get away with it" (see below GP17) and not refer for communication problems, GPs reported a higher level of prioritisation for referring patients with swallowing disorders:

... safety is more the issue, and communication, like I was saying, we kind of end up feeling like we can get away with it because family find creative ways around things... whereas from a swallowing point of view, because we know it's having a great effect on risks of pneumonias or sort of serious stuff, you know, then I think it takes the focus. So I would agree that would be where we would prioritise our referral. (GP 17)

This is interesting because it suggests then that communication ability is not "serious stuff". While swallowing assessment was "of course" offered, the perception was that communication intervention was superficial and more than likely would be limited to the basic provision of a communication board of pictures:

We're fairly lucky. We have access to speech pathology services so they can potentially produce a board for them to point at pictures and they assess their swallow as well, of course. (GP 12) 
When compared to other allied health services, GPs reported knowing less about speech pathology and referring far less often:

Compared to what I know about a physio, it's much less. (GP 15)

I'd refer to physiotherapy much more frequently. (GP 21)

I think probably people don't know, Aboriginal people, especially country people, wouldn't even know what a speech therapist was. If we struggle to say what a speech therapist is imagine how their limited understanding would be... (GP 15)

Reasons why GPs did not often make referrals to speech pathology for their adult Aboriginal patients included a strong assumption that rehabilitation would have already been done soon after the stroke or TBI and that further referrals down the recovery track or once back in the community were unlikely to be of benefit:

I mean you sort of assume if they've had a major stroke, you assume they spent a period of time in a rehab unit... So you sort of assume that that's been done. (GP 6)

I think there still seems to be some sort of perception that unless you get early intervention, the ongoing intervention is not worthwhile and I think that the research doesn't support that any more both physical and speech and that in fact the brain is actually able to relearn for years afterwards. And I think that, yeah, there are a lot of people who are missing out on intervention and help to be truthful. (GP 3)

Several GPs reported that, as time went by, it became increasingly difficult to get reliable case history information on patients, to know how much therapy may have been given at a previous time, or whether any change was likely with extended times post-stroke or TBI:

But I'm not sure if the speech therapists four or five years down the track, whether their sort of practice can improve their speech, communication? I don't know. (GP 7) 
It might not probably cross my mind half the time to think about whether they'd still benefit years down the track from speech therapy. (GP 6)

Some suggested that speech pathology was unlikely to be helpful anyway, or as patients got older, both perceptions unsupported by any evidence:

Are you going to say no, you need to see a speech therapist because this is going to make a difference to the rest of your life? And it's like well, actually I think it's probably not, so let's concentrate on the diabetes. (GP11)

So she did see the speech pathologist in the stroke team. She was provided with a picture pocket communication booklet which she does not like and she prefers to use her limited speech. I think now she's 59, maybe too old to rehab later. That's my general understanding. Too old to give her any new things about speech. (GP 2)

Speech pathology services were also viewed as difficult to access, highly stretched, involving long waiting times for appointments, and sometimes providing poor feedback to the referring GP. Several participants also questioned how cost effective services were, particularly when there were limited allied health allowances under certain care plan funding arrangements:

Globally they just need more allied health resources up here. That's about the long and short of it... I have referred quite a few people to them but I've received no communication back from them. (GP 14)

On the whole it's a bit of a locked door to allied health. That's what it feels like. (GP 15)

I think you have the cost effective thing... in your mind. (GP 18)

Theme 6: Management of ACD: interpreting, family, and communication strategies 
Most commonly reported was the reliance on family, community members and AHWs to assist in various ways, including identifying those with $A C D$, and developing effective communication channels:

...the reason I've known of them is that the clinic staff or other people, other locals are able to say 'ahh, no, that one doesn't speak well' ... in this situation l've not even attempted to access support for that person because in a small community, often the community works out a way to communicate with them... a lot of the Health Workers have a very special role in being able to bridge that gap of communication... (GP 17)

GPs also noted that with time and getting to know patients, they were able to become attuned gradually to a particular patient's communication:

And we'll just spend longer with the patients and so with patients that are difficult to communicate with, it's necessary to spend a lot of time. (GP 16)

But also the other thing too is that if someone's got a communication issue, when you know them for a long time, you're much better at it. (GP15)

Family members, or AHWs were usually used in preference to formal interpreting services when Aboriginal patients did not speak English, sometimes because of the difficulties in accessing interpreters:

Families act as the kind of like the interpreter for other family members with a speech problem, don't they? Because they have tuned their ears into that speech. (GP15)

I rarely use them [formal interpreting services] to be fair... I also find it useful when an Aboriginal Health Worker might interpret for me... I haven't ever bought anyone down in person to be a formal interpreter because like it's a two-and a half hour drive, and then often there are appropriate resources within our service, so we have Health Workers or family members that that I usually feel comfortable with, and I always check that the person is ok for them to be there... and at least they've got some health training. It's not that we're just using a random family member, I guess. (GP 21)

Interestingly, one GP noted that it was easier to use an interpreting service for overseas migrants than for Aboriginal people: 
And I have used them [interpreting services] in some circumstances but we don't use them frequently. For example, I wouldn't use them as frequently as I would interpreters for other languages... if I had a patient who spoke predominantly Chinese, I would be more likely to get a Chinese interpreter than I would a patient who speaks, you know, one of the hundreds of languages... if we were trying to get someone who spoke the [Aboriginal] language, they're probably going to be a family member anyway in the interpreter service, because it probably means they're from the same community area and therefore are related in some way. In that sense the benefits of using the translator services are lost a little bit. (GP 17)

Finally, participants explained what communication strategies they might use with patients with ACD. They mentioned signing to supplement lack of verbal communication, written or pictured items for a patient to point to, increased patience and ongoing reliance on family and AHWs:

I think Indigenous people use a lot of body language and sign language and I don't claim to have skills in that area but having hung out with Indigenous people a lot I probably can interpret some of that... And so for people with speech difficulty, that probably is highly relevant. (GP11)

Potentially we could use written strategies or pointing or giving options and then going with the option that's indicated... which I probably use mostly to be fair, yep... like giving a range of options and trying to take it from there. (GP 21)

Communication strategies might be "... something that you just kind of come up with on the spur of the moment or something that the family have already come up with" (GP 18). The process was not always straightforward and communicating could be difficult and frustrating:

I don't think it is so much a problem in here because we can give them the time to try and get to the bottom of what their problem is but it can be really frustrating for patients when they are trying to communicate stuff... You need time with them to just try and help them get to the bottom of stuff. We don't have picture charts and stuff like that which I think would be really helpful. I guess we don't really have any specific aids that we use so I think we could do a hell of a lot better. (GP 3) 


\section{Discussion and Conclusions}

\subsection{Discussion}

This research has highlighted six key themes which demonstrate how GPs working across WA view their communication with Aboriginal adults with ACD due to stroke and TBI. The high rates of stroke and TBI in Aboriginal people, along with low levels of rehabilitation in the subacute period [36-38] suggest there would be potentially high visibility of persisting ACD in community and primary health care settings. However, the findings point to a low visibility of ACD on GP caseloads, for a range of possible reasons: being overshadowed by more urgent medical management; only being noticed by GPs when very obvious and severe; being missed because of difficulty distinguishing ACD in the context of language and cultural difference; and being overlooked because of GP unconscious bias and assumptions regarding Aboriginal people's aspirations and attitudes to communication. These assumptions expose possible gaps in understanding between non-Aboriginal GPs and their Aboriginal patients and they risk inadequate information provision, patient education and access to shared decision-making. GPs reported that they were unlikely to actively attend to ACD if patients did not themselves raise it as an issue. This is perhaps unsurprising, but it suggests that GPs might not fully appreciate the barriers for patients in doing this. Aboriginal people may experience challenges in engaging with GPs in consultations $[9,10,13$, 39-42], and may feel unable to express their concerns. Equally, GPs may also have problems communicating effectively with people with an $A C D$, particularly aphasia $[8,43]$. Unlike safety concerns with swallowing disorders, there was minimal GP awareness of the importance of managing communication to prevent depression, isolation, decreased input 
into life decisions, and adverse health events, all issues with increased prevalence for people with ACD $[27,44,45]$.

The difficulties described by GPs in identifying why communication was breaking down related in part to their lack of training about both ACDs (reported elsewhere in general practice [8]), and to cultural-linguistic difference. While we did not specifically explore whether this was more problematic for GPs who themselves had English as an additional language, a few participants suggested that this was relevant, and this needs further investigation. Even if an ACD was identified, GPs did not see much reason to refer to speech pathology for ongoing rehabilitation or support. They implied that: speech pathology would be a poor use of funds; would amount to little more than the provision of a communication chart; that having been offered in the acute and subacute period would have no added value further down the recovery pathway; was not effective for older people; would involve waiting lists, not be available or accessible; and would be unnecessary because the family, community or AHWs would be able to manage the ACD anyway. In a context where GP referrals to speech pathology for Aboriginal children were far more frequent, this finding suggests that they need more information about what the speech pathology profession offers to promote ongoing improvement for adults after brain injury. GPs have a gatekeeper role to services and their doubts about the availability or value of therapy for $A C D$ potentially restricts access to ongoing rehabilitation options. Lack of knowledge about ACD or speech pathology mirror a study from the United Kingdom [8] where GPs had received little training on communication disability, were unaware of its extent and range, had limited knowledge about speech and language therapy, and "simply assumed they would rely on carers"(p.51). However, while GPs' low confidence in dealing with ACD in our study 
might reflect a broader finding about limited GP knowledge on the issue and how to manage it, this study has explored the context of Aboriginal patients in WA, where there are other contextual, historical, attitudinal, linguistic and cultural factors which compound the potential for communication breakdown and under-recognition of the problem.

GPs in our study recognised the important role of AHWs in achieving culturally appropriate care, and often worked very closely with them. Reliance on health workers and family members has been reported in other studies on healthcare for Aboriginal people [47]. However, this reliance may be problematic in situations where there is no family, or where a patient is dislocated from adequate supports. GPs' low use of formal interpreting services, indeed reported as lower than for other patients where English was an additional language, is not ideal, is potentially discriminatory, and requires more attention [48]. Finally, the ad hoc, "on the spur of the moment" (GP 18) strategies to manage consultations with Aboriginal patients with ACD suggests the need for more systematic training and communication supports for GPs.

\subsection{Conclusions}

GPs are aware of the complexity of health and social issues that exist for many of their Aboriginal patients and despite Aboriginal people's wishes for holistic care, it is unsurprising that GPs prioritise issues related to medical management. While GPs acknowledge ACDs and report the value of good communication with their patients, they find ACDs difficult to recognise and disentangle from cultural and linguistic differences. Their lack of prioritising of communication ability after brain injury may compound the disadvantage and disempowerment experienced by many Aboriginal people within the health system and beyond. 


\subsection{Practice implications}

GPs report finding it difficult to communicate effectively with Aboriginal patients with $A C D$, particularly in a context where English may not be a first language, where there are linguistic and cultural differences, and complex medical and social histories. GPs would benefit from further training to better understand $A C D$ in an Aboriginal cultural context, and how it impacts on patients' lives. GPs need support to promote effective communication in consultations, including around information provision, shared decision-making, collaborations with health workers and interpreters where required, and appropriate ongoing referral.

Funding: This work was supported by the National Health and Medical Research Council (NHMRC) Project Grant \#1046228, 2013-2016.

\section{Declaration of Interest}

No potential conflict of interest was reported by the authors.

\section{Author statement}

Deborah Hersh: Conceptualization; Data curation; Formal analysis; Writing - original draft Elizabeth Armstrong: Conceptualization; Funding acquisition; Project administration; Data curation; Formal analysis; Writing - original draft Meaghan McAllister: Conceptualization; Project administration; Data curation; Formal analysis;

Natalie Ciccone: Conceptualization; Data curation; Formal analysis; Judith Katzenellenbogen: Conceptualization; Writing - review \& editing 
Juli Coffin: Validation; Conceptualization; Writing - review \& editing

Sandra Thompson: Conceptualization; Writing - review \& editing

Colleen Hayward: Writing - review \& editing

Leon Flicker: Conceptualization; Writing - review \& editing

Deborah Woods: Writing - review \& editing 


\section{References}

[1] J.M. Katzenellenbogen, T. Vos, P. Somerford, S. Begg, J.B. Semmens, J.P.Codde, Burden of stroke in Indigenous Western Australians: A study using data linkage, Stroke. 42 (2011) 1515-1521. https://doi/10.1161/STROKEAHA.110.601799

[2] J.M. Katzenellenbogen, E. Atkins, S. Thompson, D. Hersh, J. Coffin, L. Flicker, C. Hayward, N. Ciccone, D. Woods, M. Greenland, M. McAllister, E. Armstrong, Missing Voices: Profile, extent and 12-month outcomes of non-fatal traumatic brain injury in Aboriginal and nonAboriginal adults in Western Australia using linked administrative records, J Head Trauma Rehabil. 33 (2018) 412-423. https://doi/10.1097/HTR.0000000000000371

[3] L. Jamieson, J.E. Harrison, J.G. Berry, Hospitalisation for head injury due to assault among Indigenous and non-Indigenous Australians, July 1999- June 2005. Med J Aust. 188 (2008) $576-579$.

[4] S.T. Engelter, M. Gostynski, S. Papa, M. Frei, C. Born, V. Ajdacic-Gross, F. Gutzwiller, P.A. Lyrer, Epidemiology of aphasia attributable to first ischemic stroke: Incidence, severity, fluency, etiology, and thrombolysis, Stroke. 37 (2006) 1379-1384.

https://doi/10.1161/01.STR.0000221815.64093.8c

[5] J.M. Katzenellenbogen, E. Atkins, S. Thompson, D. Hersh, J. Coffin, L. Flicker, C. Hayward, N. Ciccone, D. Woods, M. McAllister, E.M. Armstrong, Missing Voices: Profile and extent of acquired communication disorders in Aboriginal and non-Aboriginal adult stroke survivors in Western Australia using linked administrative records, Int J Stroke. 11 (2016) 103-116. https://doi/10.1177/1747493015607521 
[6] J. Law, K. Bunning, S. Byng, S. Farrelly, B. Heyman, Making sense in primary care: levelling the playing field for people with communication difficulties, Disabil Soc. 20 (2005) 169-184. http://dx.doi.org/10.1080/09687590500059267

[7] M.A. Morris, M.L. Clayman, K.J. Peters, A.L. Leppin, A. LeBlanc, Patient-centred communication strategies for patients with aphasia: Discrepancies between what patients want and what physicians do, Disabil Health J. 8 (2015) 208-215.

http://dx.doi.org/10.1016/j.dhjo.2014.09.007

[8] J. Murphy, Perceptions of communication between people with communication disability and general practice staff, Health Expect 9 (2006) 49-59. http://doi.org/10.1111/j.1369-

\section{$\underline{7625.2006 .00366 . x}$}

[9] P. Abbott, J. Reath, E. Gordon E, D. Dave, C. Harnden, W. Hu, E. Kozianski, C. Carriage, General Practitioner Supervisor assessment and teaching of Registrars consulting with Aboriginal patients - is cultural competence adequately considered? BMC Med Educ. 14 (2014) 167. https://doi/10.1186/1472-6920-14-167

[10] S. Shahid, L. Finn, D. Bessarab, S.C. Thompson, 'Nowhere to room... nobody told them': Logistical and cultural impediments to Aboriginal peoples' participation in cancer treatment, Aust Health Rev. 35 (2011) 235-241. https://doi/10.1071/AH09835

[11] A. Cass, A. Lowell, M. Christie, P.L. Snelling, M. Flack, B. Marrnganyin, I. Brown, Sharing the true stories: improving communication between Aboriginal patients and healthcare workers. Med J Aust. 176 (2002) 466-470.

[12] E. Kendall, L. Barnett, Principles for the development of Aboriginal health interventions: culturally appropriate methods through systemic empathy, Ethn Health. 20 (2015) 437-52. https://doi/10.1080/13557858.2014.921897 
[13] I. Lin, P. O’Sullivan, J. Coffin J, D.B. Mak, S. Toussaint, L. Straker, 'I can sit and talk to her': Aboriginal people, chronic low back pain and healthcare practitioner communication, Aust Fam Physician. 43 (2014) 320-324.

[14] A. Lowell, E. Maypilama, S. Yikaniwuy, S, E. Rrapa, R. Williams, S. Dunn, “Hiding the story": Indigenous consumer concerns about communication related to chronic disease in one remote region of Australia, Int J Speech Lang Pathol. 14 (2012) 200-208. https://doi/10.3109/17549507.2012.663791

[15] S. Shahid, D. Bessarab, Howat P, S.C. Thompson, Exploration of the beliefs and experiences of Aboriginal people with cancer in Western Australia: a methodology to acknowledge cultural difference and build understanding, BMC Med Res Methodol. 9 (2009) 1-8. https://doi/10.1186/1471-2288-9-60

[16] D.A. Kenny, W. Veldhuijzen, T. van der Weijden T, A. LeBlanc, J. Lockyer, F. Légaré, C. Campbell, Interpersonal perception in the context of doctor-patient relationships: A dyadic analysis of doctor-patient communication, Soc Sci Med. 70 (2010) 763-768. http://doi.org/10.1016/i.socscimed.2009.10.065

[17] A. Pilnick, R. Dingwall, On the remarkable persistence of asymmetry in doctor/patient interaction: A critical review, Soc Sci Med. 72 (2011) 1374-1382.

https://doi/10.1016/i.socscimed.2011.02.033

[18] C. Roberts, S. Sarangi, Theme-oriented discourse analysis of medical encounters, Medical Education. 39 (2005) 632-640. https://doi/10.1111/i.1365-2929.2005.02171.x [19] N. Fatahi, B. Mattsson, J. Hasanpoor, C. Skott, Interpreters' experiences of general practitioner-patient encounters, Scand J Prim Health Care. 23 (2005) 159-163. https://doi/10.1080/02813430510018509 
[20] C. Roberts, B. Moss, V. Wass, S. Sarangi, R. Jones, Misunderstandings: a qualitative study of primary care consultations in multilingual settings, and educational implications, Med Educ. 39 (2005) 465-475. https://doi/10.1111/j.1365-2929.2005.02121.x

[21] E. Armstrong, G. McKay, D. Hersh, Assessment and treatment of aphasia in Aboriginal Australians: Linguistic considerations and broader implications for cross-cultural practice, J Clin Prac in Speech-Lang Pathol. 19 (2017) 4-11.

[22] D. Eades, Aboriginal English and the law: Communicating with Aboriginal English Speaking clients. A handbook for legal practitioners, Queensland Law Society, Brisbane, 1992.

[23] I. Mushin, R. Gardner, Silence is talk: Conversational silence in Australian Aboriginal talk-in-interaction. J Pragmat. 41 (2009) 2033-2052.

https://doi.org/10.1016/i.pragma.2008.11.004

[24] D. Eades, Language and the law: White Australia v. Nancy, in: M. Walsh, C. Yallop, (Eds.), Language and culture in Aboriginal Australia, Aboriginal Studies Press, Canberra, 1993, pp. 181-191.

[25] W. Jennings, G.K. Spurling, D.A. Askew, Yarning about health checks: barriers and enablers in an urban Aboriginal medical service, Aust J Prim Health. 20 (2014) 151-157. https://doi.org/10.1071/PY12138.

[26] M.L. van Mierlo, C. Schröder, C.M. van Heugten, M.W. Post, P.L. de Kort, J.M. VisserMeily, The influence of psychological factors on health-related quality of life after stroke: a systematic review, Int J Stroke. 9 (2014) 341-34. https://doi.org/10.1111/ijs.12149 
[27] M. Cruice, L. Worrall, L. Hickson, Perspectives of quality of life by people with aphasia and their family: Suggestions for successful living, Top Stroke Rehabil. 13 (2006) 14-24. https://doi.org/10.1310/4JW5-7VG8-G6X3-1QVJ

[28] E. Graessel, R. Schmidt, W. Schupp, Stroke patients after neurological inpatient rehabilitation: a prospective study to determine whether functional status or health-related quality of life predict living at home 2.5 years after discharge, Int J Rehabil Res. 37 (2014)

\section{2-219. https://doi.org/10.1097/MRR.0000000000000060}

[29] L. Worrall, S. Sherratt, P. Rogers, T. Howe, D. Hersh, A. Ferguson, B. Davidson, What people with aphasia want: Their goals according to the ICF, Aphasiology. 25 (2011) 309-22. https://doi.org/10.1080/02687038.2010.508530

[30] E. Armstrong, D. Hersh, J.M. Katzenellenbogen, J. Coffin, S.C. Thompson, N. Ciccone, C. Hayward, L. Flicker, D. Woods, M. McAllister, Study Protocol: Missing VoicesCommunication difficulties after stroke and traumatic brain injury in Aboriginal Australians, Brain Impair. 16 (2015) 145-156. https://doi.org/10.1017/Brlmp.2015.15

[31] M. Sandelowski, Whatever happened to qualitative description? Res Nurs Health. 23 (2000) 334-340.

[32] V. Minichiello, R. Aroni, T. Hays, In-depth interviewing, third ed., Pearson Education Australia, Sydney, Australia, 2008.

[33] M.Q. Patton MQ. Qualitative Research and Evaluation Methods, third ed, Sage, Thousand Oaks, CA, 2002.

[34] QSR International Pty Ltd, NVivo qualitative data analysis software. QSR International Pty Ltd, Doncaster, Vic, Australia, 2006. 
[35] V. Braun, V. Clarke, Using thematic analysis in psychology, Qual Res in Psychol. 3 (2006) 77-101. http://dx.doi.org/10.1191/1478088706qp063oa

[36] E. Kendall, C.A. Marshall, Factors that prevent equitable access to rehabilitation for Aboriginal Australians With Disabilities: The Need for Culturally Safe Rehabilitation, Rehabil Psychol. 49 (2004) 5-13. http://dx.doi.org/10.1037/0090-5550.49.1.5

[37] M.F. Kilkenny, D.M. Harris, E.A. Ritchie, C. Price, D.A. Cadilhac, Hospital management and outcomes of stroke in Indigenous Australians: evidence from the 2009 Acute Care National Stroke Audit. Int J Stroke. 8 (2013) 164-171. https://doi.org/10.1111/j.17474949.2011.00717.x.

[38] S. Gauld, S. Smith, M.B. Kendall, Using participatory action research in communitybased rehabilitation for people with acquired brain injury: from service provision to partnership with Aboriginal communities, Disabil Rehabil. 33 (2011) 1901-1911. https://doi.org/10.3109/09638288.2010.550382

[39] B. Andrews, P. Simmons, I. Long, R. Wilson, Identifying and overcoming the barriers to Aboriginal access to General Practitioner services in rural NSW, Aust J Rural Health. 10 (2002) 196-201.

[40] T. Freeman, T. Edwards, F. Baum, A. Lawless, G. Jolley, S. Javanparast, T. Francis, Cultural respect strategies in Australian Aboriginal primary health care services: beyond education and training of practitioners, Aust NZ J Public Health 38 (2014) 355-61. https://doi.org/10.1111/1753-6405.12231

[41] S.T. Liaw, I. Hasan, V. Wade, R. Canalese, M. Kelaher, P. Lau, M. Harris, Improving cultural respect to improve Aboriginal health in general practice: A multi-methods and multi-perspective pragmatic study, Aust Fam Physician. 44 (2015) 387-392. 
[42] A. Thomson, S. Morgan, P. O’Mara, A. Tapley, K. Henderson, M. van Driel, C.

Oldmeadow, J. Ball, J. Scott, N. Spike, L. McArthur, P. Magin, Clinical encounters of Australian general practice registrars with Aboriginal and Torres Strait Islander patients, Aust NZ J Public Health. 40 (2016) S75-S80. https://doi.org/10.1111/1753-6405.12412

[43] M.A. Morris, M.L. Clayman, K.J. Peters, A.L. Leppin, A. Leblanc, Patient-centered communication strategies for patients with aphasia: Discrepancies between what patients want and what physicians do, Disabil and Health J. 8 (2015) 208-215. https://doi.org/10.1016/i.dhjo.2014.09.007

[44] M.C. Brady, A.M. Clark, S. Dickson, G. Paton, R.S. Barbour, The impact of stroke-related dysarthria on social participation and implications for rehabilitation, Disabil Rehabil. 33 (2011) 178-186. https://doi.org/10.3109/09638288.2010.517897

[45] B. Hemsley, M. Werninck, L. Worrall, "That really shouldn't have happened": People with aphasia and their spouses narrate adverse events in hospital, Aphasiology. 27 (2013) 706-722. https://doi.org/10.1080/02687038.2012.748181

[47] S. Shahid, A. Durey, D. Bessarab, S.M. Aoun, S.C. Thompson, Identifying barriers and improving communication between cancer service providers and Aboriginal patients and their families: the perspective of service providers, BMC Health Serv Res. 13 (2013) 460. http://www.biomedcentral.com/1472-6963/13/460 [48] A.P. Ralph, A. Lowell, J. Murphy, T. Dias, D. Butler, B. Spain, J.T. Hughes, L. Campbell, B. Bauert, C. Salter, K Tune, A. Cass, Low uptake of Aboriginal interpreters in healthcare: exploration of current use in Australia's Northern Territory, BMC Health Serv Res. 17 (2017) 733. https://doi.org/10.1186/s12913-017-2689-y 